\title{
Analysis of Employment Status and Countermeasures of Contemporary College Students
}

\section{Yu Li}

Sichuan Agricultural University, Admissions and Employment Office, Chengdu, Sichuan, China, 611130

Keywords: Analysis, Contemporary College Students, Employment Status, Countermeasures

\begin{abstract}
With the popularization of higher education and the deepening reform of college graduate employment system, the number of college graduates has risen year by year, while the employment rate has been declining with the slowdown of Chinese economic development. The employment problems of college students mainly manifest the following aspects: the number of employment increases, the employment rate declines, the employment satisfaction is not high, the phenomenon of employment discrimination is serious, employment has regional difference, there is a deviation of career choices among college students. Since 2003, the Chinese government has adopted a series of policies and measures to promote the employment of university graduates and has achieved some progress. However, it has not fundamentally alleviated the employment problem of college graduates in China. The employment problem of college students is caused by many factors, such as the imbalance of employment structure, the prominent contradiction between supply and demand, the failure of the content and structure of school education to adapt to social development. The solution to the employment problem of college students in China depends on not only the reform of the government policy system but also on the reform of the school education system and the change of graduates' concept of employment.
\end{abstract}

\section{Introduction}

In recent years, the employment of college graduates has become a topic of universal concern. Especially since 2003, post-expansion enrollment of ordinary colleges and universities began to enter the job market, while Chinese higher education has entered a stage of popularization. Therefore, the employment situation of college students is even more serious. In response to this situation, many people have conducted in-depth analysis and research, and each put forward different responses [1]. Looking at their research, we can summarize the following aspects: From the perspective of social transformation, we think that the factors influencing the employment of college graduates in the transitional period are system, economy, culture education, individual qualities and ways of thinking; from the perspective of economics, The influencing factors include the institutional division of the labor market, the family economy, the number of contact units, the expected return, the social capital, the regional economy and the unbalanced economic development between urban and rural areas. From the perspectives of employers and graduates, the influencing factors. There are comprehensive quality of college students, academic level, employment concept, level of knowledge and ability; from the social environment, school education, the influencing factors are supply and demand imbalances, professional settings, school brand, professional differences, the limitations of higher education system, employment environment Complex and changeable; from a macro perspective, the influencing factors are the government, colleges and universities, the employment market, employers and graduates themselves; from the perspective of labor market supply and demand, the influencing factors are population quantity and quality, economic development level and growth rate, industrial structure, employment system, etc.

\section{The Employment Problems of College Students in China}

The employment policy of undergraduates in China has experienced three stages: the unification of unification under the planned economy, the employment policy of undergraduates under the 
combination of the planned and the commodity markets, and the independent choice of employment under the deepening of socialist market economy reform. Under the system of planned economy, China has implemented the principle of unifying the whole system and organizing work in an overall manner. There is basically no employment difficulty for undergraduates. Two-way choice phase, graduates mainly from colleges and universities recommend employment to the community, employing units merit admission, this stage, the employment problem is not obvious. At present, our country is practicing self-employment, "most graduates will enter the market according to their own abilities and conditions to participate in the competition, instead of relying on administrative measures to ensure employment by the state." Graduates' employment problems began to emerge, especially in the first batch of enrollments after graduation and the employment of our college students is more and more difficult [2].

Job satisfaction is not high, the phenomenon of employment discrimination is serious. According to the latest "China University Students Employment Report" shows that from October 2012 to April 2013 survey shows that higher vocational college, undergraduate, master's degree Graduate enrollment rates were $32 \%, 35 \%$ and $26 \%$, respectively, which were lower than the same period in 2012. The employment rate of university graduates in 2013 has dropped significantly compared with the previous years. In the meantime, according to the "Report", $8.5 \%$ of unemployed people still have fresh graduates in 2012. From the perspective of employment satisfaction, the employment satisfaction of the 2012 fresh graduates (including postgraduate, undergraduate and vocational college) is only about 55\% within half a year of graduation, and among them, the employment satisfaction of graduates from "211" institutions High, reaching 62\%, general satisfaction with employment of undergraduate $57 \%$. The reason is due in part to the less popular professions, the higher professional constraints and the harsh working environment, so the pressure of competition is relatively small, but this cannot represent the trend of the entire employment rate. In contrast, the less-employed majors include law, English, animation and so on. As a result of the greater competition, less demand and less professionalism, these majors have been ranked as the last few in the employment rate for several years in a row.

There are regional differences in employment and graduates are concentrated in developed areas, as mentioned above, $70 \%$ of the total number of graduates who chose to work in the three major regional economies for 2012 graduates. According to Michael's graduation survey, only 2\% of graduates first wish is to go to the district or township employment, to developed cities to seek development has been deeply rooted in the hearts of college graduates. In the meantime, the great economic difference in our country has also led to the reluctance of college graduates to go to grassroots development. Then the reality shows that the talent market in developed areas has become saturated, causing job seekers in colleges and universities often encounter setbacks in finding jobs in major cities. At the same time, job-seeking oversupply tends to occur in some grassroots areas or the northwestern part of the country, with most of the work without People interested, unable to recruit people. Although the government has formulated various preferential policies to attract undergraduates to support grassroots units and support the northwest region, their actual results have been negligible [3]. This disparity has led to labor resources cannot be reasonably configured, college students employment is narrow, the unemployment rate increased.

There is a bias in career choices among college students. Under the influence of traditional college education ideas and old employment ideas, many college students find their employment orientation wrong, and some of them still locate themselves as senior social talents. At the time of employment, these people bent on working relaxed and well-paid businesses, bent on working as civil servants or public institutions, while others only wanted to work for foreign companies. Of course, this is inseparable from Chinese national conditions. For example, if a civil servant is admitted to China, it means obtaining a "golden rice bowl." It is easy to work, well-paid and well-paid. This means that everyone is on a par with civil service positions. Taking the 2013 National Examination as an example, the national civil service examinations for 13 years registered a total of 20,839 candidates and the number of applicants was nearly 2 million. The ratio of recruiting students reached 90: 1 , indicating the intensity of competition. It is important to explain 
the deviation of career choices among university students and to change and guide the state system. However, the most important thing is to change the concept of university values and traditional employment. Not everyone can be admitted as a civil servant or as a public institution. The blind chase is not conducive to college students' employment. When choosing careers, some college students find it hard to accept some jobs that look rather grassroots and hard-working, often resulting in an embarrassing situation of "high status cannot be achieved while low status is not good".

\section{The Factors Affecting the Employment of Contemporary College Students}

The reform of our education system lags far behind the reform of the economic system. The quality of education in schools is weak and the quality of students is not perfect. The education concept of exam-oriented education is still deep-rooted. It can be described as "a serious shortage of supply, an obviously unbalanced structure, an extremely imperfect system, and a rigid mechanism of inflexibility". The most basic nature of the university is academic. How to stick to the academic quality of the university and maintain the independent academic nature of the university is an important issue that must be paid attention to in the current reform of the Chinese higher education system. The unbalanced development of education in our country still exists. In order to promote the development of education for all, our government and people have made tremendous efforts and achieved considerable achievements. However, due to its vast territory, large population and low economic level, the development of EFA still faces many difficulties.

School conditions, limitations. First, school conditions for running school. The school teachers, teaching and experimental facilities, the basis of scientific research, discipline construction determines the school's educational level and ability to run a school, is to determine the quality of the main external factors, but also affect the employment of students the most important factor. The second is to carry out employment guidance for college students. Rich employment information for graduates to create more employment opportunities, there is no good employment channels and cutting-edge information, and then outstanding graduates cannot realize their own life value. At present, many colleges and universities employment guidance is weak, and their employment guidance courses are only for graduates to open, simply through several forums, lectures, lectures and even completed the employment guidance. On the one hand, the higher the reputation of the school, the more trust the employer will have in the school graduates. In other conditions are equal, the employer to choose the school's graduates more likely than other school graduates. On the other hand, the better the school reputation, you can attract more employers come here, to participate in the school's job fair. This greatly increases the amount of employment information for graduates and creates more job opportunities for graduates [4].

Now employers no longer meet a certificate, a diploma, a transcript, a certificate, and the like, they not only require graduates with strong theoretical knowledge, but also more focused on the ideological conduct of college students, communicative competence, expressive ability, practical ability and other aspects of quality training. The employer sees an innovative talent who will do things for people instead of a mediocre one who only speaks on paper. Some employers lack the long-term vision does not want to spend energy and financial training of new people. This is indeed an impassable threshold for fresh graduates.

\section{The Initiatives to Promote the Employment of College Student}

The government should speed up the reform of the education system to meet the needs of social development. The government and other administrative departments should properly support the development of colleges and universities, give colleges and universities more freedom rights and minimize interference in the internal affairs of schools. We should change the concept of education, get rid of the shackles of traditional education, and support schools to promote quality education in an all-round way, conduct thorough education reform and improve the education system.

Colleges and universities should try to get rid of the shackles of government and other 
administrative agencies, develop their own characteristics of education, promote quality education in an all-round way and cultivate innovative and complex talents with unique characteristics. In order to further strengthen the construction of the teaching staff, in the process of formulating professional personnel training programs, we must scientifically formulate the objectives and specifications for personnel training and provide education for the society in accordance with the requirements of "thick foundation, wide caliber, strong ability, high quality and innovation", In accordance with the needs of society rational allocation of professional. To strengthen students' general education and basic education, broaden the professional area, the implementation of classification training, pay attention to the personality development of college students.

Schools should regularly conduct social surveys and graduates employment tracking survey, tracking feedback, combined with the social experience of previous graduates and social needs, appropriate adjustments to the structure of knowledge in order to adapt to social development. To strengthen the guidance of employment, college students notion of employment cannot be cultivated overnight, understanding of society and occupation requires a process, which requires colleges and universities not to confine career guidance education to graduates, but should be for all College students, graduates should be the focus of guidance for all college students to carry out full employment guidance, so that the full guidance and key guidance combined with the employment guidance throughout the entire process of college education [5].

\section{Conclusions}

The various problems that have emerged in the process of social and economic development in our country have also had a profound impact on the employment situation of college students, including the restriction on the total economic output and the restriction on the structure. The most important part of the employment problem of college students lies in the increase of total employment. With the vigorous development of our country's economy and culture, the education level has also been greatly improved. Nowadays, Chinese higher education has been on par with developed countries and has entered the stage of popularization and popularization. What followed was the gradual increase in the number of college graduates each year, combined with the squeeze of non-employed graduates in previous years, resulting in a huge supply of labor in the entire job market.

\section{References}

[1] Wang Ruihong. College students' business opportunities usher in an opportunity [J]. Chinese college students employment. 2017 (17).112

[2] Zhou Junying. Study on long-term mechanism to improve employment and entrepreneurship ability of special group of graduates in Henan Province [J] Industry and Technology Forum. 2017 (19).39

[3] Gan Zhongtao. "Internet +" era local colleges and universities to explore employment promotion ability of entrepreneurship [J]. Reform and opening up. 2017 (18).77

[4] Dongyue Jin, Wu Gang. Local college graduates to enhance employment and entrepreneurship Based on the practice of educating people perspective [J]. Journal of Huaiyin Institute of Technology. 2012 (06).63

[5] Zhang Mei Rong. Reflections on improving the employment ability of freshmen[J]. Chifeng University Journal (Philosophy and Social Science Edition). 2009 (11).128 